\title{
Role of MRI in the Diagnosis of Fetal Anomalies at 18-20 Weeks Gestational Age
}

\author{
Akshaya Mohan ${ }^{1}$, Rajeswaran Rangasami ${ }^{2}$, Anupama Chandrasekharan ${ }^{3}$, Indrani Suresh ${ }^{4}$, Suresh Seshadri ${ }^{5}$, Chitra Andrew $^{6}$
}

\begin{abstract}
Aim: To evaluate the role of magnetic resonance imaging (MRI) in the diagnosis of fetal anomalies at 18-20 weeks of gestation.

Materials and methods: We retrospectively reviewed fetal MRI examinations done during June 2014-May 2018. There were 23 referrals for fetuses at 18-20 weeks gestation, out of the total 330 referrals for fetal anomaly evaluation. The MR images were read independently by two radiologists. When there was discrepancy in the diagnosis, the final diagnosis was arrived by consensus.

Results: There were 23 examinations for fetuses at 18-20 weeks of gestational age that showed 27 anomalies. This included 22 central nervous system (CNS), 2 thoracic, 1 gastrointestinal, 1 genitourinary, and 1 miscellaneous anomalies. In the 23 pregnant women, termination of pregnancy was carried out in 18 and three women were managed conservatively. Follow-up was lost in two women.

Conclusion: MRI is a complementary tool to ultrasound in the evaluation of fetal anomalies. With advancement of MRI scanner technology and growth of knowledge, more number of anomalies can be diagnosed at or before 20 weeks gestational age.

Clinical significance: Diagnosing fetal anomalies at or before 20 weeks by MRI is challenging because of increased fetal movements and small size of the fetus. However, improved techniques may facilitate early detection. This becomes a necessity in some countries where elective termination of pregnancy is allowed only up to 20 weeks. This article highlights that MRI can also provide additional information on select cases during 18-20 weeks.

Keywords: Antenatal MRI, Fetal anomalies, Pregnancy, Prenatal MRI.

Journal of South Asian Federation of Obstetrics and Gynaecology (2019): 10.5005/jp-journals-10006-1714
\end{abstract}

\section{INTRODUCTION}

Ultrasonography is the primary modality for fetal imaging because of its relative low cost, lack of harmful effects to the fetus or mother, and real-time imaging. ${ }^{1}$ However, there are limitations, including small field of view (FOV), limited soft-tissue acoustic contrast and beam attenuation by the adipose tissue, poor image quality in oligohydramnios, and limited visualization of the posterior fossa.

Fetal MRI is an extremely useful complementary tool in the evaluation of fetal anomalies especially those belonging to the central nervous system (CNS) and thorax. ${ }^{2-5}$ There is a limited role for MRI in detecting cardiac anomalies. Fetal anomalies are usually diagnosed at 18-24 weeks of gestation by sonography and MRI. Diagnosing fetal anomalies at or before 20 weeks is challenging because of increased fetal movements, small size of the fetus, and the ongoing organ development within the fetus. ${ }^{1}$ With availability of improved ultrasound (US) and MRI scanners, the anomalies are being diagnosed early. It is challenging but may become a reality to be able to diagnose most anomalies before 21 weeks with improved imaging scanners. ${ }^{1}$ This becomes a necessity in some countries where medical termination of pregnancy is allowed only up to 20 weeks. We studied the role of MRI in the evaluation of fetal anomalies at 18-20 weeks gestation. We could not find a similar article in our literature search.

\section{Materials and Methods}

We reviewed fetal MRI examinations done between June 2014 and May 2018. Institutional ethical clearance was obtained. Out of the 330 examinations, 23 belonged to the gestational age of 18-20 weeks and 307 belonged to the gestational age more than 20 weeks. MRI was performed within 4 days of US examination.

\footnotetext{
${ }^{1-3}$ Department of Radiology, Sri Ramachandra Institute of Higher Education and Research, Chennai, Tamil Nadu, India

${ }^{4-6}$ Department of Fetal Medicine, Mediscan Systems, Chennai, Tamil
} Nadu, India

Corresponding Author: Rajeswaran Rangasami, Department of Radiology, Sri Ramachandra Institute of Higher Education and Research, Chennai, Tamil Nadu, India, Phone: +91 9841311552, e-mail: rajeswaranrangasami@gmail.com

How to cite this article: Mohan A, Rangasami R, Chandrasekharan A, et al. Role of MRI in the Diagnosis of Fetal Anomalies at 18-20 Weeks Gestational Age. J South Asian Feder Obst Gynae 2019;11(5):292-296.

Source of support: Nil

Conflict of interest: None

The fetal MR examinations were performed after obtaining an informed written consent for clinical indications. The MR images were read independently by two radiologists with more than 10 years of experience in fetal imaging and had access to clinical and US data. The interobserver variability was low (2\%). When there was discrepancy in the diagnosis, the final decision was arrived by consensus. Since ours is a referral institution for fetal MRI, the pregnant women returned to original clinics/hospitals after the MR examination. The follow-ups were obtained from telephonic conversation with the patients or referral doctor.

MR images were obtained from a 1.5 T MRI scanner (Avanto Siemens, Erlangen, Germany) with a 16-element torso array coil. The MR sequences included (1) $T_{2}$-weighted half-Fourier acquisition single shot turbo spin echo (HASTE) (TR: 900 ms, TE: 90 ms, FOV: $24-28 \mathrm{~cm}$, matrix: $256 \times 256$, number of excitations: 1 , slice thickness:

() The Author(s). 2019 Open Access This article is distributed under the terms of the Creative Commons Attribution 4.0 International License (https://creativecommons. org/licenses/by-nc/4.0/), which permits unrestricted use, distribution, and non-commercial reproduction in any medium, provided you give appropriate credit to the original author(s) and the source, provide a link to the Creative Commons license, and indicate if changes were made. The Creative Commons Public Domain Dedication waiver (http://creativecommons.org/publicdomain/zero/1.0/) applies to the data made available in this article, unless otherwise stated. 
3-4 mm, intersection gap: $0.2 \mathrm{~mm}$ ), (2) $T_{1}$-weighted TURBO FLASH (TR: $160 \mathrm{~ms}$, TE: $4.5 \mathrm{~ms}$, flip angle: $70^{\circ}$, FOV: $24-28 \mathrm{~cm}$, matrix: $256 \times$ 154, number of excitations: 1, slice thickness: $4.5 \mathrm{~mm}$, intersection gap: $0.2 \mathrm{~mm}$ ), and (3) Echo-planar DWI (TR: 5,000 ms, TE: $101 \mathrm{~ms}$, FOV: 24-28 cm, matrix: $192 \times 192$, slice thickness: $4.5 \mathrm{~mm}$, intersection gap: $0.2 \mathrm{~mm}$ ). Using a $b$ value of 0 and 800 seconds $/ \mathrm{mm}^{2}$ the $T_{2}$ and diffusion-weighted images were obtained whenever required, e.g., fetal intracranial hemorrhage.

\section{Results}

In our study, there were 23 MR examinations for fetuses at 18-20 weeks of gestational age that showed 27 anomalies. There were 22 CNS anomalies, 2 thoracic, 1 each of the genitourinary and gastrointestinal system, and 1 miscellaneous anomaly (Table 1). In the CNS, there were six cases of agenesis of corpus callosum, two cases of ventriculomegaly, two cases of encephalocele, and one case each of Chiari malformation, Dandy-Walker malformation, unilateral cerebellar hypoplasia, vermian hypoplasia, Blake's pouch cyst, and others as described in Table 2. Spinal anomalies detected were diastematomyelia, absent sacrum, myelomeningocele, and sacrococcygeal teratoma. Thoracic anomalies included eventration and congenital pulmonary airway malformation (CPAM), gastrointestinal anomalies included omphalocele, and genitourinary anomalies included bladder exstrophy. There was good correlation with sonography in 22 of 27 anomalies and complementary in 5 of 27 anomalies. This included where the MR diagnoses were hemimegaloencephaly, sacrococcygeal teratoma, germinal matrix hemorrhage with ventriculomegaly, eventration, and sacral agenesis. In the 23 pregnant women, termination of pregnancy was carried out in 18 and three women were managed conservatively. Follow-up was lost in two women.

\section{Discussion}

Ultrasound is the primary modality in the evaluation of fetuses. However some anomalies may not be clearly visible on US due to technical limitations or nonspecific appearance of the anomaly. Excellent soft tissue contrast, multiplanar capability, and obtaining a larger FOV are important benefits of MRI. MRI was useful in confirming agenesis of corpus callosum (Fig. 1) and identifying the neural content of myelomeningocele and encephalocele. $\mathrm{MRI}$ is complementary to US in assessing the posterior fossa. ${ }^{6-8}$ In some patients who were referred as posterior fossa fluid collection after sonography, MRI was very useful to assess the brain stem vermian angle and the degree of development of vermis, cerebellar hemispheres. This helped in further classification of posterior fossa anomalies. Blake's pouch cyst (Fig. 2), Dandy-Walker malformation (Fig. 3), unilateral cerebellar hypoplasia, vermian hypoplasia and) were identified at 18-20 weeks in our study. MRI could provide additional information in diastematomyelia (Fig. 4) and sacrococcygeal teratoma (Fig. 5) when they could only be suspected on sonography. In a meta-analysis done by Antonio et al. including 531 fetuses (in 22 studies), the prevalence of additional CNS anomalies that were missed by sonography and detected only by MRI was $13.7 \%$, and the prevalence of additional CNS abnormalities that were missed at prenatal imaging and detected only after delivery was $18.2 \% .^{9}$

It was possible to identify eventration on MRI by defining the elevated diaphragm. Omphalocele, bladder exstrophy, and congenital pulmonary airway malformation (CPAM) were also
Table 1: Fetal MRI findings with gestational age and the corresponding prenatal US findings

\begin{tabular}{|c|c|c|c|}
\hline $\begin{array}{l}\text { Gestational } \\
\text { weeks }\end{array}$ & USG findings & MRI findings & Follow-up \\
\hline 20 & $\begin{array}{l}\text { Unilateral } \\
\text { ventriculomegaly }\end{array}$ & $\begin{array}{l}\text { Hemimegalen- } \\
\text { cephaly }\end{array}$ & TOP \\
\hline 19 & $\begin{array}{l}\text { Diaphragmatic } \\
\text { hernia }\end{array}$ & $\begin{array}{l}\text { Eventration of left } \\
\text { hemidiaphragm }\end{array}$ & C \\
\hline $19-20$ & $\begin{array}{l}\text { Ventriculomeg- } \\
\text { aly, cerebellar } \\
\text { hypoplasia }\end{array}$ & $\begin{array}{l}\text { Ventriculomegaly, } \\
\text { cerebellar hypoplasia }\end{array}$ & TOP \\
\hline $19-20$ & $\begin{array}{l}\text { Cerebellar } \\
\text { hypoplasia }\end{array}$ & $\begin{array}{l}\text { Unilateral cerebellar } \\
\text { hypoplasia }\end{array}$ & C \\
\hline 20 & Possible ACC & ACC & TOP \\
\hline $19-20$ & Ventriculomegaly & $\begin{array}{l}\text { PACC, germinal } \\
\text { matrix hemorrhage } \\
\text { with intraventricular } \\
\text { extension }\end{array}$ & TOP \\
\hline 20 & $\begin{array}{l}\text { Multiseptate cystic } \\
\text { lesion in perineal } \\
\text { region }\end{array}$ & $\begin{array}{l}\text { Sacrococcygeal } \\
\text { teratoma }\end{array}$ & TOP \\
\hline 20 & Ventriculomegaly & $\begin{array}{l}\text { Ventriculomegaly } \\
\text { with bilateral cerebral } \\
\text { parenchymal } \\
\text { thinning }\end{array}$ & TOP \\
\hline 20 & $\begin{array}{l}\text { Possible } \\
\text { diastemetomyelia }\end{array}$ & Diastematomyelia & TOP \\
\hline $19-20$ & Possible ACC & ACC & TOP \\
\hline 19 & $\begin{array}{l}\text { Posterior fossa fluid } \\
\text { collection }\end{array}$ & $\begin{array}{l}\text { Dandy-Walker } \\
\text { malformation }\end{array}$ & TOP \\
\hline 19 & $\begin{array}{l}\text { Possible } \\
\text { myelomeningocele }\end{array}$ & Myelomeningocele & TOP \\
\hline 20 & Possible ACC & $\mathrm{ACC}$ & TOP \\
\hline 20 & Possible ACC & ACC & TOP \\
\hline 20 & $\begin{array}{l}\text { Possible Blake's } \\
\text { pouch cyst }\end{array}$ & Blake's pouch cyst & C \\
\hline 19 & $\begin{array}{l}\text { Encephalocele with } \\
\text { omphalocele }\end{array}$ & $\begin{array}{l}\text { Encephalocele with } \\
\text { omphalocele }\end{array}$ & TOP \\
\hline $19-20$ & Possible ACC & ACC & TOP \\
\hline 19 & Micrognathism & Micrognathism & TOP \\
\hline 18 & CPAM-type I & $\begin{array}{l}\text { CPAM-type I/ } \\
\text { esophageal } \\
\text { duplication cyst }\end{array}$ & LFU \\
\hline 20 & Bladder exstrophy & $\begin{array}{l}\text { Bladder exstrophy } \\
\text { with absent sacrum }\end{array}$ & TOP \\
\hline $19-20$ & Possible ACC & $\mathrm{ACC}$ & TOP \\
\hline $19-20$ & Encephalocele & Encephalocele & TOP \\
\hline 20 & $\begin{array}{l}\text { Posterior fossa fluid } \\
\text { collection }\end{array}$ & Vermian hypoplasia & LFU \\
\hline
\end{tabular}

TOP, termination of pregnancy; C, conservatively managed; LFU, lost follow-up

identified by MRI. In a study involving 40 pregnant women with fetuses in 17-38 weeks gestational age and showing 60 anomalies (during 2005-2007), Rajeswaran et al. could detect anomalies like omphalocele, cystic hygroma, and ventriculomegaly between 17 weeks and 20 weeks of gestation by fetal MRI. ${ }^{2}$ Conte et al. retrospectively studied fetuses within 25 weeks of gestational age who had undergone both prenatal and postnatal MR imaging 
Table 2: Systemwise classification of the fetal malformation

\begin{tabular}{ll}
\hline System and anomalies & No. \\
\hline Central nervous system & 6 \\
ACC & 2 \\
Ventriculomegaly & 2 \\
Encephalocele & 1 \\
Dandy-Walker malformation & 1 \\
Myelomeningocele & 1 \\
Unilateral cerebellar hypoplasia & 1 \\
Cerebellar hypoplasia & 1 \\
Diastematomyelia & 1 \\
Blake's pouch cyst & 1 \\
Hemimegalencephaly & 1 \\
Vermian hypoplasia & 1 \\
Chiari 2 malformation & 1 \\
Absent sacrum & 1 \\
Germinal matrix hemorrhage with intraventricular extension & 1 \\
Sacrococcygeal teratoma & 1 \\
Thorax & \\
Eventration of left hemidiaphragm & 1 \\
Lung cyst & 1 \\
Genitourinary system & \\
Bladder exstrophy & 1 \\
Gastrointestinal & \\
Omphalocele & 1 \\
Miscellaneous & \\
Micrognathism & \\
\hline
\end{tabular}

of the brain between 2002 and $2014 .^{10}$ A total of 109 fetuses were included in this study and 111 malformations were detected. Some of the anomalies diagnosed were complete callosal agenesis, callosal hypoplasia, vermian hypoplasia, cerebellar hypoplasia, focal polymicrogyria, and ventriculomegaly.

Fetal organs develop and increase in size throughout gestation, and so some of the anomalies can be better diagnosed during the late second or third trimesters of pregnancy. ${ }^{11}$ Some anomalies that can be missed by 20 weeks scan or develop later are microcephaly, cystic lesions, migrational anomalies of brain, ventriculomegaly, certain renal anomalies, and dysgenesis of the corpus callosum. ${ }^{12}$ Functioning capacity of various organs also increases as gestational age and so some anomalies related to function (e.g., urogenital) are better detected in the third trimester. Sometimes minor findings like ventricular prominence become a significant finding like grossly dilated ventricles in the third trimester. ${ }^{13}$ Infections, ischemic events, and hemorrhage can occur in any period of gestation. Hence, a third-trimester US scan may also be needed to rule out anomalies occurring later.

The limitations of early fetal MR imaging are increased fetal movement, small size, and ongoing development of organs. With the improvement in coil technology, we are able to achieve a higher channel body/torso coil. This along with the improved MR machine technology is able to produce a higher signal-to-noise (SNR) ratio. The phase oversampling method available for the HASTE sequence enables us to scan shorter FOV with a good SNR ratio. With advancements in parallel imaging techniques, the MR sequences are being performed with less time. Thus, we are able
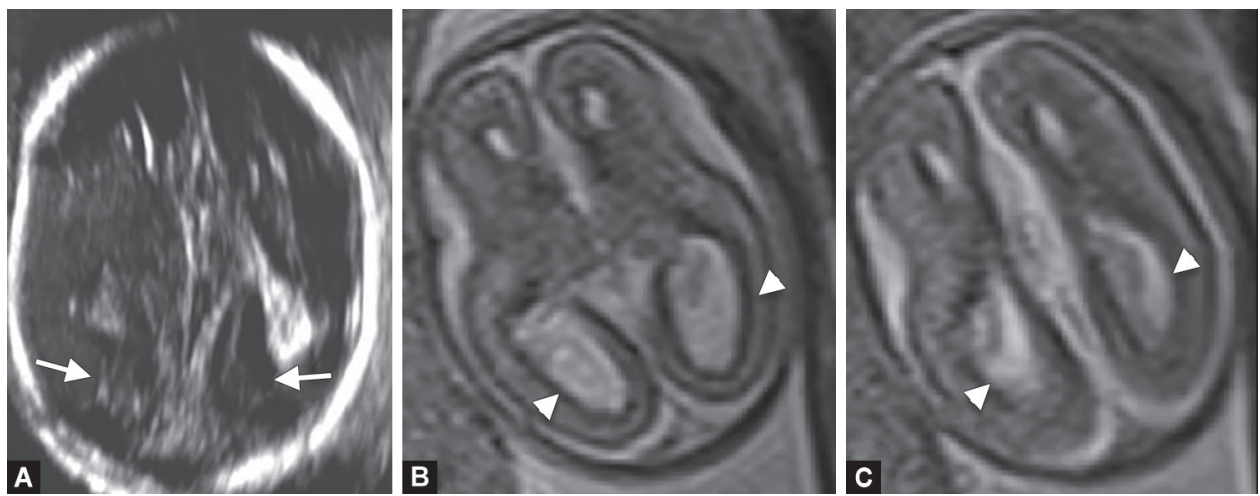

Figs 1 A to C: (A) A 19-week fetus showing colpocephaly on US (arrows); (B and C) Axial MRI sections show absent cavum septum pellucidum and parallel orientation of bilateral lateral ventricles (arrowheads) confirming agenesis corpus callosum
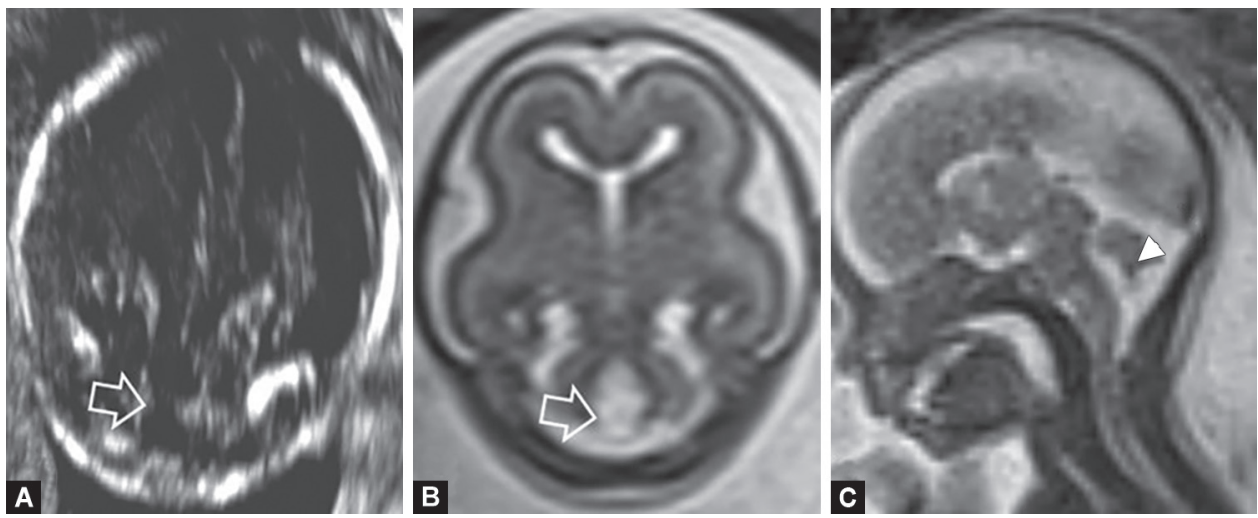

Figs 2A to C: (A) Sonography; (B) MRI axial images in a 20-week fetus show a posterior fossa fluid collection communicating with the IV ventricle (open arrows); (C) Sagittal MRI image shows elevation of the inferior medullary velum (arrowhead). The brainstem vermian angle was $27^{\circ}$ suggesting the Blake's pouch cyst 

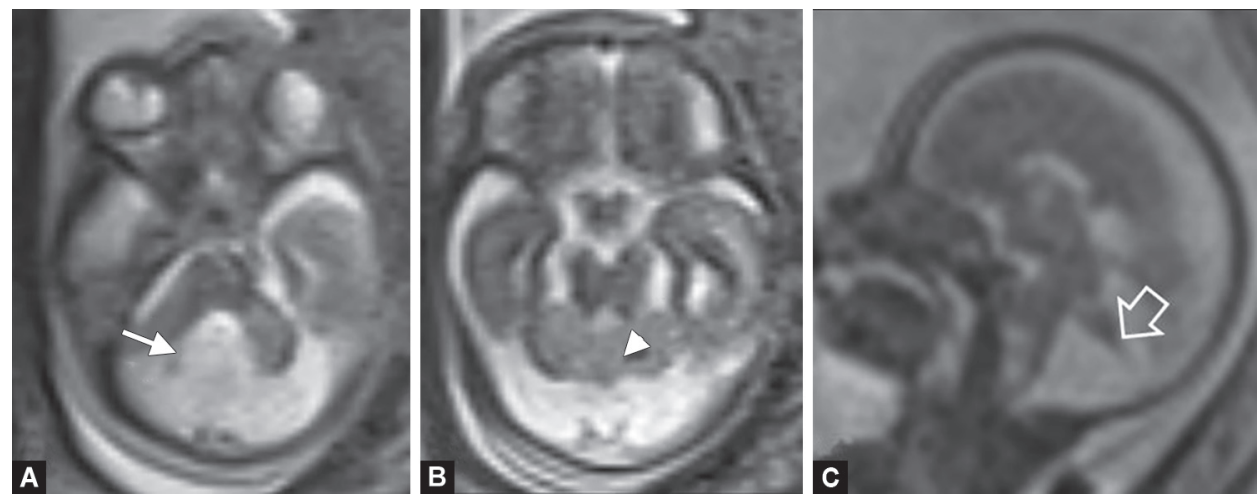

Figs 3 A to C: (A and B) Axial MRI images of a 19-week fetus showing the dilated fourth ventricle, which is seen to be continuous with a cystic area (arrow). Only the superior tip of the vermis is visualized (arrowhead); (C) Sagittal MRI image shows elevation of the inferior medullary velum (open arrow). The brainstem vermian angle was $65^{\circ}$ suggesting Dandy-Walker malformation
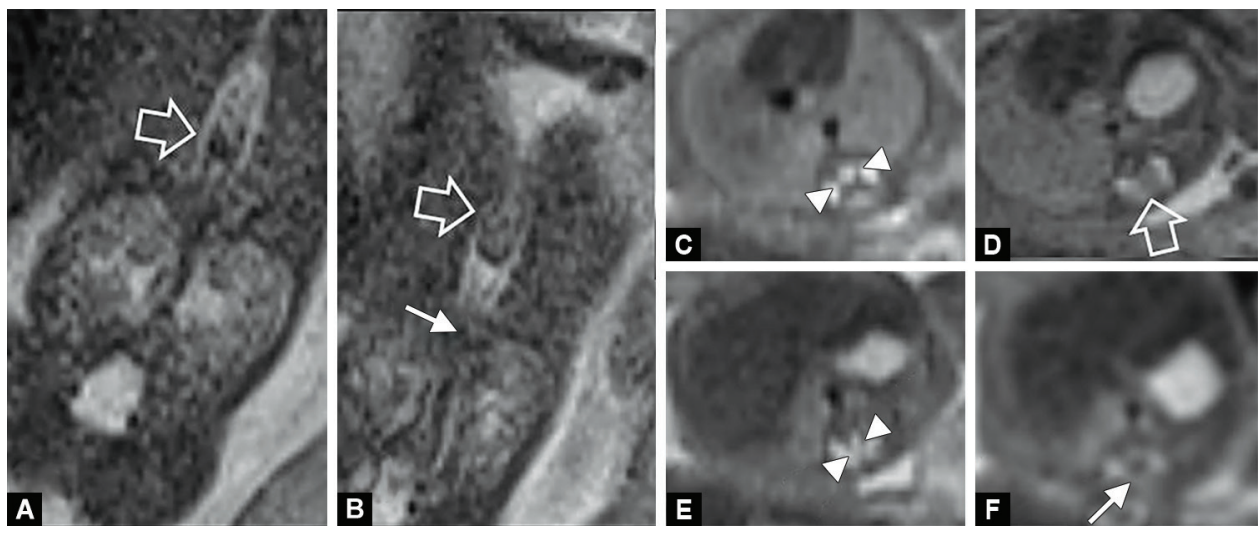

Figs 4A to F: (A and B) Coronal sections in a 20-week fetus show a widened spinal canal in the mid-dorsal region with a bony septum (open arrows). The two spinal cords unite in the lower dorsal level (arrow); (C to F) Axial sections show two spinal cords (arrowheads) and an intervening septum (open arrows) in the mid-dorsal region suggesting diastematomyelia. The spinal cords unite in the lower dorsal level (arrow)
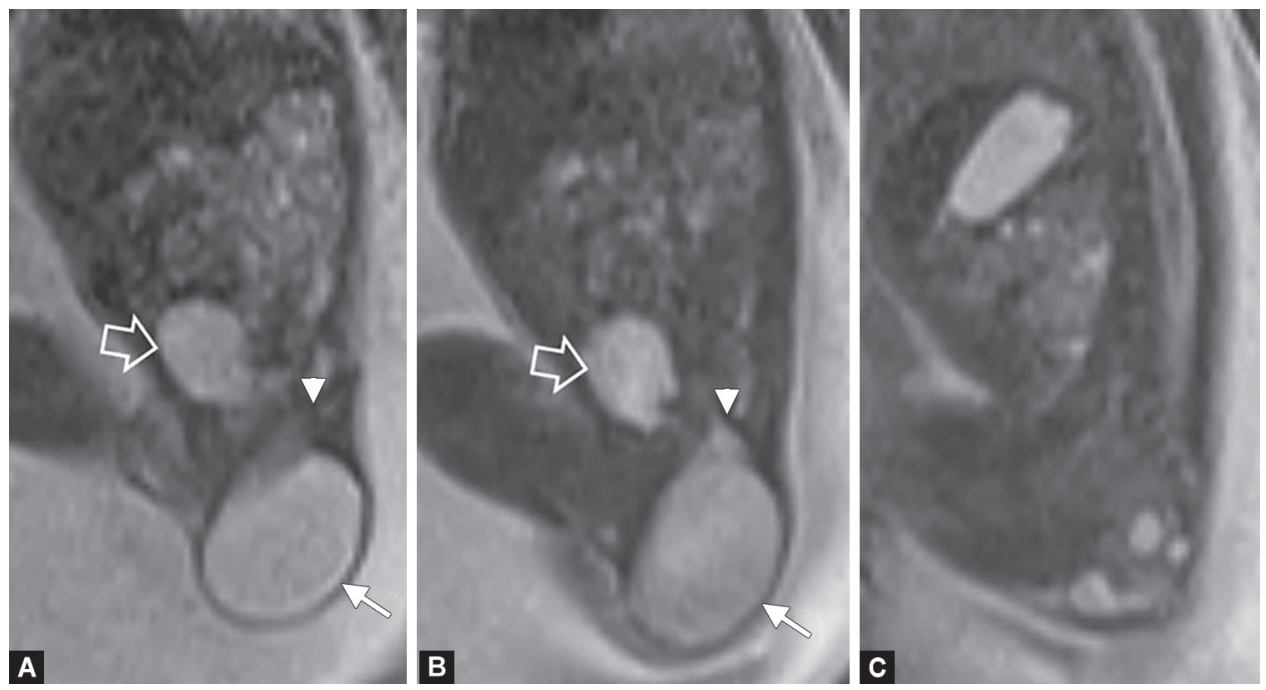

Figs 5A to C: Sagittal MR images of a 20-week fetus showing a cystic lesion in the sacrococcygeal region with extrafetal (arrows) and intrapelvic components (arrowheads) suggesting type II sacrococcygeal teratoma. The urinary bladder is displaced anterosuperiorly (open arrows)

to overcome fetal movements to a reasonable extent. There is still scope to improve all these parameters. Though we are able to achieve good contrast resolution with MRI, the spatial resolution can still be improved.
In some countries, medical termination of pregnancy is allowed only up to 20 weeks. Hence, it is important to diagnose anomalies accurately prior to 20 weeks, which will help the couple to make informed choices about further management in the pregnancy. 


\section{Conclusion}

Ultrasound is the primary diagnostic tool for detection of fetal anomalies at 18-20 weeks. While significant number of referrals for fetal MRI is still in the late second trimester and third trimester, $\mathrm{MRI}$ can also provide additional information on select cases during 18-20 weeks.

\section{Clinical Significance}

Diagnosing fetal anomalies at or before 20 weeks by MRI is challenging because of increased fetal movements and small size of the fetus. However, improved techniques may facilitate early detection. This becomes a necessity in some countries where medical termination of pregnancy is allowed only up to 20 weeks. This article highlights that MRI can also provide additional information on select cases during 18-20 weeks.

\section{References}

1. Kashyap N, Pradhan M, Singh N, et al. Early detection of fetal malformation, a long distance yet to cover! present status and potential of first trimester ultrasonography in detection of fetal congenital malformation in a developing country: experience at a tertiary care centre in India. J Pregnancy 2015;2015:623059. DOI: 10.1155/ 2015/623059.

2. Rajeswaran R, Chandrasekharan A, Joseph S, et al. Ultrasound versus $\mathrm{MRI}$ in the diagnosis of fetal head and trunk anomalies. J Matern Fetal Neonatal Med 2009;22(2):115-123. DOI: 10.1080/ 14767050802488238.

3. Glenn OA, Barkovich AJ. Magnetic resonance imaging of the fetal brain and spine: an increasingly important tool in prenatal diagnosis, part 1. AJNR Am J Neuroradiol 2006;27(8):1604-1611.
4. Rossi AC, Prefumo F. Additional value of fetal magnetic resonance imaging in the prenatal diagnosis of central nervous system anomalies: a systematic review of the literature. Ultrasound Obstet Gynecol 2016;47(6):690-697. DOI: 10.1002/uog.14900.

5. Rajeswaran R, Chandrasekharan A, Joseph S, et al. Magnetic resonance signal intensity measurements in the diagnosis of fetal central nervous system anomalies. J Matern Fetal Neonatal Med 2012;25(6):679-686. DOI: 10.3109/14767058.2011.594116.

6. Sohn YS, Kim MJ, Kwon JY, et al. The usefulness of fetal MRI for prenatal diagnosis. Yonsei Med J 2007;48(4):671-677. DOI: 10.3349/ ymj.2007.48.4.671.

7. Glenn OA. MR imaging of fetal brain. Pediatr Radiol 2010;40(1):68-81. DOI: 10.1007/s00247-009-1459-3.

8. Limperopoulos C, Robertson Jr RL, Khwaja OS, et al. How accurately does current fetal imaging identify posterior fossa anomalies? Am J Roentgenol 2008;190(6):1637-1643. DOI: 10.2214/AJR.07.3036.

9. D'Antonio F, Khalil A, Garel C, et al. Systematic review and metaanalysis of isolated posterior fossa malformations on prenatal ultrasound imaging (part 1): nomenclature, diagnostic accuracy and associated anomalies. Ultrasound Obstet Gynecol 2016;47(6): 690-697. DOI: 10.1002/uog.14900.

10. Conte G, Parazzini C, Falanga G, et al. Diagnostic value of prenatal MR imaging in the detection of brain malformations in fetuses before the 26th week of gestational age. AJNR Am J Neuroradiol 2016;37(5):946-951. DOI: 10.3174/ajnr.A4639.

11. Yinon $Y$, Katorza E, Nassie DI, et al. Late diagnosis of fetal central nervous system anomalies following a normal second trimester anatomy scan. Prenat Diagn 2013;33(10):929-934. DOI: 10.1002/ pd.4163.

12. Reddy UM, Filly RA, Copel JA. Prenatal imaging: ultrasonography and magnetic resonance imaging. Obstet Gynecol 2008;112(1):145-157. DOI: 10.1097/01.AOG.0000318871.95090.d9.

13. Vijaykumar M, Shailaja $M$, Nilofar $M$, et al. Detection of structural fetal anomalies in third trimester which usually remains undetected in second trimester. Int J Appl Res 2017;3(2):158-162. 